\title{
Signifying Truth: Augustine, Lacan, and a Theory of Language
}

\author{
Zachary Tavlin ${ }^{1}$ \\ University of Washington
}

\begin{abstract}
In this paper, I will show how a retroactive reading of Augustine by Lacan can help us understand more clearly the process of the subject's accession to language and interhuman relations on the path toward understanding. I will distinguish the Lacanian reading from the reductive Wittgensteinian reading, placing Augustine's theory on language and learning in a broader context, particularly with regard to the process of subjectivization. Lacan explicitly read Augustine's scenario of the jealous child in the Confessions, and devoted an early seminar to his theory of language and signification; I propose to take these readings seriously while showing that their psychoanalytic relevance extends further into Augustine's theory of language and subjectivity than perhaps is normally recognized. Ultimately, though Lacan can help to clarify the stakes in which the linguistic subject is ontologically limited (and in which 'corporeal', symbolic reality is truthdeficient), this reading will help to show where Augustine's theology has specifically informed his theory of language and its subject, and where its revisions must fail (or set out somewhere on their own).
\end{abstract}

\section{Introduction}

In this essay, I will develop a reading of St. Augustine's theory of language that breaks with Wittgenstein's critique, which reduces Augustine's concern to the mere correlation between meanings and words. First, I will show how the semiotic distinction between natural and conventional signs allows one to conceive of a more complex linguistic structure. Then I will demonstrate how the distinction between the inner and outer word suggests a space in language that provides the structure's support despite its constitutive position outside of it. From there, I will read Jacques Lacan (in particular, aspects of his theory's 'structural' phase) in order to develop this idea according to his concept of the Big Other. In modeling language around a 'lack', and in relation to the social, I further develop an idea of the subject of language, which grants both Lacan and Augustine a system that can support the kind of speech acts that Wittgenstein's picture didn't account for. Finally, I discuss a few of the ontological and methodological differences between Augustine and Lacan, and consider their relevance to this project. ${ }^{2}$

1 Correspondence concerning this article should be addressed to Zachary Tavlin, 5024 Sand Point Place, Seattle, WA, 98105. E-mail: ztavlin@uw.edu. 


\section{Augustine against Wittgenstein}

Wittgenstein reads Augustine's 'picture' of language as the very oversimplification in theory that a rigorous philosophy of language must overturn. For Wittgenstein, Augustine's language is merely a naming process; signifiers simply correspond with objects in the world. He opens his Philosophical Investigations by quoting from Confessions Augustine's account of the transformation of sounds into designations:

I noticed that people would name some object and then turn towards whatever it was that they had named. I watched them and understood that the sound they made when they wanted to indicate that particular thing was the name which they gave to it, and their actions clearly showed what they meant, for there is a kind of universal language, consisting of expressions of the face and eyes, gestures and tones of voice... So, by hearing words arranged in various phrases and constantly repeated, I gradually pieced together what they stood for, and when my tongue had mastered the pronunciation, I began to express my wishes by means of them. In this way I made my wants known to my family and they made theirs known to me, and I took a further step into the stormy life of human society, although I was still subject to the authority of my parents and the will of my elders (Augustine, 1961, p. 29).

Wittgenstein claims that,

[these] words...give us a particular picture of the essence of human language. It is this: the individual words in language name objects - sentences are combinations of such names. In this picture of language we find the roots of the following idea: every word has a meaning. This meaning is correlated with the word. It is the object for which the word stands (Wittgenstein, 1953, p. 2).

But there is more going on here than Wittgenstein is willing to acknowledge. It is not just that the child is able to repeatedly match the signifier to the referent and build a vocabulary based on an extensive collection of those one-to-one relations. There are also external relations (he "hear[s] words arranged in various phrases") that suggest, even on a primitive level, a differential structure. There are wishes being made, a 'human society' being encountered. And, importantly, there is a suggestion here of the performative 
speech act: to make one's 'wants known' is, at least in part, to attempt to alter a state of affairs through language (one articulates a desire not just to state that the desire exists, but as a means of fulfilling it).

Consider a distinction made by Augustine in De Doctrina Christiana between natural signs and conventional signs. "Natural signs are those which, apart from any intention or desire of using them as signs, do yet lead to the knowledge of something else" (Augustine, 1995, p. 34), as in the common case of smoke betraying fire. But conventional signs "are those which living beings mutually exchange in order to show, as well as they can, the feelings of their minds, or their perceptions, or their thoughts" (Augustine, 1995, p. 34). So Augustine attributes a fundamental epistemic function to the sign, which alone gathers signifier and signified in a parallel relation, but also distinguishes convention (and therefore language) with an added 'intention to signify'. This intention, or the place of the will extended to the sphere of communication, must be seen (in its effects) in language and outside of the domain of the semiotic proper at the same time.

The 'intention to signify' is the guarantor of conventional consistency, though it is not what guarantees communication (which is a much more mysterious process). Rather, it guarantees that the signifiers in use are a part of some language's structure, or at least intend to be (which covers cases where an enunciation's syntax does not conform to convention but is 'close enough' to fulfill intelligibility). However, it's important to note that convention, for Augustine, entails artificiality in comparison to something else. In the $20^{\text {th }}$ century, when social and political processes are so often foundational, artificiality and superficiality are used as positive terms to connote a plane of immanence structuralist language asserts that there is nothing else but the differential relations themselves, and the arbitrariness of the signifier is language's bedrock. And indeed, Ake Bergvall succinctly describes the general similarities between structuralist linguistics and Augustine's theory of language (and joins Lacan himself in doing so):

Part of Augustine's theory is strikingly modern; only with Ferdinand de Saussure did linguistics and semiology catch up with it. In contrast to earlier simplistic descriptions of a two-way relationship between res, the thing, and verba, the spoken word that points to the res, Augustine introduced a third factor: the human subject. The human mind forms a mental concept of the res, which it then translates into verba. Augustine's sign, like Saussure's, therefore contained two parts: a signifier that is primarily the spoken word, and a signified that is not the thing itself but a mental concept of the thing...Although Augustine does not discuss the arbitrariness of the sign in terms of Saussure's difference he is aware of the practical implications of such a view. "In some languages," he concedes, "there are words that cannot be translated 
into the idiom of another language" (OCD 2.11). Translation, because two different speech communities are involved, is therefore no simple one-to-one equation (Bergvall, 1993, p. 24).

But there is an aspect of Augustine's system that does not translate easily into the structuralist framework. As Richard Glejzer notes, "Unlike structural linguistic models, both scholasticism and psychoanalysis are founded on an imperative to consider a knowledge that resists signification, to bare the signifiers that ground ontology within an epistemology" (Glejzer, 1997, p. 106). ${ }^{2}$ For Augustine, that ontological ground involves the relation between logos and the Word, which correlates to a process of the inner word's incarnation in speech. Thought is inner speech, which carries with it an intention - inner speech is always turned toward something. Outer speech, likewise, intends towards something, even if it's not limited to constatives (Augustine is well aware of language's performative dimension). Speech, which is the primary form of language, is the inner word made flesh:

Thus in a certain fashion our word becomes a bodily sound by assuming that in which it is manifested to the senses of men, just as the Word of God became flesh by assuming that in which it too could be manifested to the senses of men. And just as our word becomes sound without being changed into sound, so the Word of God became flesh, but it is unthinkable that it should have been changed into flesh. It is by assuming it, not by being consumed into it, that both our word becomes sound and that Word became flesh (Augustine, 1991, p. 411).

The inner word is not in a language; in order for the linguistic incarnation to take place, the inner word congeals into an image of words the subject intends to speak (in a

2 The project of his essay is to find in the scholastic tradition an "ontological radicalism" consonant with psychoanalysis, "where epistemology is itself an effect of an ontological impossibility, an impossibility that the scholastics recognized as real in knowledge and language" (Glejzer, 1997, p. 109). For Glejzer, this is a broad historical project: "It is this ontological radicalism at the basis of medieval epistemology that Descartes will eventually bracket and dismiss, a radicalism that will then similarly serve as the basis of Lacan's return to Freud." Of course, Augustine is not a scholastic, and his work clearly preceded the scholastic tradition. Still, Glejzer's insight is helpful here; the "ontological radicalism" he locates in the scholastics is already there in Augustine's philosophy of language, and thus his historical project could easily incorporate Augustine. 
particular language) before being fully materialized (Augustine, 1991, p. 410). Thus, thought is not informed by conventionally conditioned linguistic categories. There is a formal transformation that occurs before the signifier-signified relation can be established. But the product of this transformation is one of lack, since we are stuck signifying things with words (as opposed to things, as God is capable of) (Augustine, 1991, p. 418).

For Augustine, a true word, beyond the sense of the purely conventional, would be a correlation between its outer and inner meanings (which is something Wittgenstein simply couldn't see). Purely conventional meaning is a meaning of lack, since its signifier names objects outside of the position of enunciation (the subject), thus in some sense killing the object. The signifier itself, indeed, only exists insofar as its use aims at the void or lack in the center of the object; we would not need words if we were not in some constitutive way estranged from the wholeness of the object. But "God can be understood to have an everlasting Word co-eternal with himself" (Augustine, 1991, p. 419). This is what our (outer) words intend toward, although they necessarily fail, since the subject cannot be complete in the way the trinity is in its absolute simplicity.

What Wittgenstein ignores is the structural position of the inner word in Augustine's account. That is, signs and the power of speech are an effect of the inner word, which is unconventional and thus exists outside of the word-meaning (and signifier-signified) correlation. In his Remarks on Frazer's Golden Bough, Wittgenstein appears to turn Augustine's, 'Let me know thee, O my Knower; let me know thee even as I am known', into one of many substanceless "call[s] to God on every page of the Confessions" (Wittgenstein, 1979, p. 1). That is, Wittgenstein's worst mistake is to ignore the performative aspect, both of the 'call to God' in providing the bedrock of a theory of language, and the concomitant production of (conventional) truth by language. As seen in the previous passage from De Trinitate, the relationship between the inner and outer word is analogous to the relationship between the Word of God and Christ incarnate. By emptying Augustine's appeal to God and truth of all theoretical content, he reduces the central authority around which the collection of signifiers circulate (and occupy their positions in language) to a mere gesture or ritual that obscures the edifice of language itself. In order to read Augustine's theory of language in a way that takes seriously his claims about truth and the self, it might be helpful to find a similar, secular account of language to which we can then apply Augustine's role of the inner word in a way that's theoretically significant. Thus, we move to Lacan.

\section{To Lacan (and Back)}

For Lacan, reality is structured for the subject according to a system of symbols; it is a seemingly coherent structure of differential relations that apply at a parallel to a set of signifiers. However, there is necessarily a lack around which the system circulates. In language there are signifiers without signifieds, and there is an unreality in experiential space that covers up its inconsistency. This is a necessary byproduct of the (linguistic) subject, which is nothing but the inconsistency of reality itself. That is, subject (and therefore the enunciation) is a void, not a positive ontological entity; it is nothing but the unrest of the concept, the impossibility of any entity being equal to itself. So the subject 
occurs because (symbolic ${ }^{3}$ ) reality is out of joint, or in some structural sense deficient. This is reconciled by the Big Other, a symbolic authority to which the subject (often unknowingly) appeals.

The Big Other is not just something the subject appeals to, though; it is something it is shaped by:

Is it with the gifts of Danaoi (the Greeks who laid siege to Troy) or with the passwords that give them their salutary non-sense that language, with the law begins? For these gifts are already symbols, in the sense that symbol means pact and that they are first and foremost signifiers of the pact that they constitute as signified, as is plainly seen in the fact that the objects of symbolic exchange - pots made to remain empty, shields too heavy to be carried, sheaves of heat that wither, lances stuck into the ground - all are destined to be useless, if not simply superfluous by their very abundance (Lacan, 1977, p. 61).

So it is not just the content of the signifier (which is arbitrary) or its correlation with a signified (and all such interrelated correlations) that's sufficient for language but a sphere of relations between subjects that provides a means for which language can be used, and which the linguistic subject cannot opt out of without losing language itself. It appears most obviously in the case of the 'gesture meant to be refused," which has no content other than the establishment or maintenance of relations between two subjects.

One of Lacan's early (1954) seminars deals explicitly with Augustine's theory of language; entitled De locutionis significatione, and initiated by Father Louis Beirnaert, here Lacan claims that "the linguists, in as much as we are entitled to make up one large family through the ages bearing this name, linguists, have taken fifteen centuries to rediscover, like a sun which has risen anew, like a dawn that is breaking, ideas which are already set out in Augustine's text [De Magistro], which is one of the most glorious one could read" (Lacan, 1991, p. 249). Indeed, Lacan goes as far as to say that "[everything] I have been telling you about the signifier and signified is there," including the structure of the relationship between signifier and signifier and signifier and signified, and the inconsistencies and asymmetries around which performativity is generated.

3 For our purposes it is sufficient to equate the 'symbolic' with conventional language.

${ }^{4}$ It may be good etiquette to offer my bed to a weary traveler, and it may be good etiquette for him to refuse - this exchange, however, is not neutral, and it confirms a particular social arrangement. 
Lacan interprets a section of Augustine's dialogue on "the difference between communication by signals and the exchange of interhuman speech" as establishing "the element of intersubjectivity" in language (Lacan, 1991, p. 250). For Augustine, speech is "a teaching," not reducible merely to a play of information but instead tending toward a notion of "truth." When, in the dialogue, Augustine and Adeodatus encounter the word nihil in their analysis of a line from the Aeneid, they show that "it is impossible to deal with language by referring the sign to the thing term by term" (Lacan, 1991, p. 252). What this 'truth' must ensure is precisely the intersubjectivity beyond the domain of oneto-one correspondences between sign and referent, the bedrock that breaks one out of the "dialectic of pointing," since if "every pointing is a sign, it is an ambiguous sign"6 (Lacan, 1991, p. 253).

Lacan's reading of the ambiguity of signs in Augustine's theory is not merely a "semantic ambiguity," but also a "subjective ambiguity": "[Augustine] admits that the very subject who is telling something very often does not know what he is telling us, and tells us more or less than he means to" (Lacan, 1991, p. 260). Thus, linking the subject to language through an account of the subject's relation to the linguistic structure becomes imperative here. For instance, in other places, Lacan found the following anecdote of Augustine's to be filled with uncommon significance: "I have myself seen jealousy in a baby and know what it means. He was not old enough to talk, but, whenever he saw his foster-brother at the breast, he would grow pale with envy" (Augustine, 1961, p. 28).

He repeatedly invokes this story as a representation of subject formation in the 'mirror stage' (where the infant first sees his reflection as himself and other than himself). The following features that can be drawn from this passage are most significant: a rivalrous encounter with a double that precedes language and a desire for a lack (which becomes the objet petit $a^{7}$ ).

There is a fallenness in the case of the child (and ultimately in the case of the 'split' subject of language), desiring forbidden fruits and milk. Where this is allegorized into a conflict between man and God, Lacan transmutes it into a dialectic between subject and other. If one cannot explain language without subjectivity (or, at the very least, the subject's constitutive relation to reality and the other through social language), then a theory of language merges with a theory of the subject. Thus, originary social rivalry and recognition is tied to linguistic convention - this link is implicit in Augustine, but rather explicit for Lacan.

But it's important to recognize that it isn't the theme of jealousy that lends the anecdote its Lacanian significance (and accounts for its re-citation throughout his work). The key

\footnotetext{
${ }^{5}$ In addition, Lacan notes that, for Augustine, "Prayer here touches on the ineffable. It does not belong in the field of speech" (Lacan, 1991, p. 250). This is a further point missed by Wittgenstein.

6 "Because if the rampart is pointed out to you, how are you to know that it really is the rampart, and not, for example, its rough quality, or its green, grey, etc?"

7 Though this term is not important here, it is another way to describe the symbolic's lack (and it's ultimate equivalent with the linguistic subject). "It is precisely because the object $a$ is removed from the field of reality that it frames it" (Alain-Miller, 1984, p. 28).
}

Language and Psychoanalysis, 2013, 2 (2), 64-76

http://dx.doi.org/10.7565/landp.2013.0007 
observation is indeed that, in the structure of the Confessions itself, the tension of early subject formation is followed by an account of language and social formation:

Augustine's trajectory from the preverbal to the verbal parallels the odyssey of the mirror-stage child from the specular $I$ to the social $I$, from the narcissistic conflict with a fraternal double to the symbolic order where the paternal law ("the will of my elders") prevails. Yet, despite occasional ambiguities in Lacan's own formulations, the mirror stage does not chiefly designate a moment or event in the progress (developmental) narrative of the child. Rather, it involves a psychical structure that is also an existential situation (Barzilai, 1999, p. 149).

It is often difficult to recognize the full ontological implications of a discourse (psychoanalysis) that is so often associated with the mechanics of 'the cure', but the Lacanian reading of Augustine fixates not so much on the anecdote in order to serve those territorial interests but to elucidate the subject's constitution in relation to the synchronic structure of language and the symbolic (or the social $I$ ).

For both Freud and Lacan, the step from the original pleasure-ego to subjectivity proper (and to the constitution of objective, symbolic reality) is the step of incorporating the difference (the gap) that separates the $I$ from the outside, from what is not- $I$. In other words, "the negativity included in the subject at its very affirmative constitution is not this or that negativity (exteriority), but the very form of negation which reveals here its real structure, namely and precisely that of with-without" (Zupancic, 2012, n. pag.). The negativity, in fact, is the subject, in the sense that it is its constitutive limit, between language and language's outside ("and it is this limit that constitutes that peculiar third dimension, which is neither outside nor inside, neither subject nor object, neither something nor absence; rather, it has the precise structure of the "with-without" ", (Zupancic, 2012, n. pag.)). The structure of the subject, then, as void or limit is intimately related to language itself, the space of which is shaped according to its absence - "the symbol, psychoanalytically speaking, is repressed in the unconscious" (Lacan, 1977, p. $80)$.

The point is that the with-without is what invests the place of the subject with its social/conventional/linguistic ' $\mathrm{I}$ '. . And further, it is what allows us to understand the

8 'With-without' is used because of its paradoxical suggestion of an ontological category that both is and is not - it is because of its effects and is not because of its unrecognizable place outside of symbolic reality.

9 "It is therefore in the very sacrifice of the certainty and self-presence of the classical subject-in its de-centering, we might say-that Augustine's "I" is born" (Mennel, 1994, p. 322). In her essay, Susan Mennel argues that Augustine's theory of subjectivity, as a deconstruction of the "metaphysics of presence" and the classical 
constitution of language itself. Language is artificial, but it is sutured by a Master Signifier that points the way toward the more 'essential' word that belongs to no language. It is no mere coincidence that one of the primary examples of the Master Signifier in Lacan is God, which admits of no temporal, empirical, enfleshed signified to point directly to. Thus it is not just that artificial language is somehow ontologically less than its non-linguistic supplement (the inner word, using Augustine's terminology), but that it contains a structural gap that points the subject in the direction of something outside of itself (the logos).

Wittgenstein's conception of language for Augustine only considered the symbolic realm of communication proper; Augustine and Lacan demonstrate the relation between the Symbolic and the Real, between language as an edifice of signifier relations and that which precedes language, is not in a language, cannot ever be in a language. Of course, the Real for Lacan differs from what it would be for Augustine (ultimately, God and the Word, but purely in relation to language, the inner word). For Lacan, the Real is indeed that which cannot possibly be symbolized, because the subject was separated from it the moment it (the subject) attained language. In fact, it need not be an actual state the subject was ever in, but a principle, a structural impossibility introduced by language, which is necessarily incomplete.

To fully understand lack in the field of language, it is important to read Lacan as differing in an important sense from the kind of post-structuralist language found in Derrida. In both cases, something in the field prevents there from being a 'metalanguage,' but for Derrida this is because the text is 'framed' by something significant, whether it's the reader's method of interpretation or a more widely construed general (surrounding) discourse. There is no 'pure' text that doesn't contain an element of interpretation, or distance towards the object of interpretation itself. That is, the text that contains differance (which is every text) contains a distance from itself inside of itself. The truth of a text is nothing more than an effect, an effect of the play or style (or pleasure) of its discursive articulation.

One of the implications of this picture is that any canonical significance of a text evaporates with the assumed link between signifier and signified. Brenda Deen Schildgen notes that:

In Jacques Derrida's version of deconstruction, because the subject (for instance, the creator or writer) of the text is absent, its referent must also be absent...[Because the text] is inscribed and therefore open to a diversity of interpretations, there is nothing fully present in its signs. Rather the trace is not the signified but another signifier

Knowing Subject, leads to a paradoxical affirmation of self in its very destitution. How is this the case? "[The] self here is affirmed instead in the alien Hebraic name of faith. Faith, [Augustine] comes to argue, is an essential mode of knowing in the world of time (which is also the world of différance) because faith accepts absence." We might respond here, in proper Lacanian fashion, that the faith that generates the self is faith in the efficiency of the signifier. 
inviting the reader to make meaning of it; any intrinsic meaning formerly associated

with any text is a fiction created by interpreters of the trace. Because the "voice" of the text is absent once it has been inscribed on a page, any notion of the presence of the word, or the Presence of the Word, is only a creative possibility, for the "logos," the meaning or voice of the text, its revelation, in traditional terms, is absent (Schildgen, 1994, p. 384).

Schildgen locates in De Doctrina Christiana an "answer" to the deconstructive assault on meaning in signs; while Augustine would agree that words or signs are ambiguous, first, for Augustine, "words in Sacred Scripture, at least, link back to the originating 'Word,"' and second, and most importantly for us here, "Augustine advances a method for interpreting written 'signs' on the grounds that they are social utilities and are intended to communicate: the meaning of verbal signs can be bridled by the context, tradition, and history with which they are aligned; words belong to communities of linguistic and symbolic signification; as a consequence, words can be interpreted incorrectly" (Schildgen, 1994, p. 388).

To make sense of this, however, while fully retaining one's skepticism towards 'metalanguage,' an entirely different presentation of the relation between signifiers (and between signifiers and signifieds) is needed. And indeed, Derrida's presentation is ultimately irreconcilable with the Lacanian picture, which emphasizes metaphor instead of metonymy. That is, if the Derridean approach demonstrates the constant motion, or metonymic sliding of signifiers that have no end or foundation in a stable structure, the Lacanian alternative is the metaphorical 'cut' that supports the play of metonymy (Lacan, 1977, p. 141). For Lacan, to even think of language as something at all significant, as conventional and in some constitutive way separate from the reality it attempts to name (though it indeed fails), it must contain a structure that prevents its collapse into things. This is the Hegelian point, that there must be an element of negativity that separates representation from the Absolute (Real), or else the subject (of language) would be unnecessary and dissipate as a position that can regard things (or name things) as other than itself. Language thus contains a lack at the center of its structure, a Master Signifier that has no signified. It is the point de capiton $^{10}$ that sutures the field of signifiers, that lends it its consistency and holism while repressing (or merely hiding, covering over) the fact that language is ultimately in-consistent.

When metalanguage is 'deconstructed,' it's shown to produce internal gaps where the position of (a speaker's) enunciation is subverted, so that no utterance in language says exactly what it's 'supposed' to say. But the position from which this is recognized, that the process of enunciation always subverts the enunciated content, is the position of metalanguage itself. That is, even the Derridean position, despite itself, recognizes the irreducibility of the subject of language, the void from which the enunciation is offered. This is the same recognition that Augustine makes when he says that we see through a

10 Or 'quilting point'. 
mirror $^{11}$ : we are not looking at a reflection of God when we seek Him, we are the mirror itself, and thus are always incomplete with regard to Him. The problem with selfawareness is that it is de-centered according to its position, and thus cannot fully appropriate itself or its utterances. To make sense of this we must read Augustine's claim that the mind, in considering itself, turns its inner gaze upon itself as something that's bound to fail, since as subject one can't fully wrap oneself around oneself. ${ }^{12}$

For Lacan, truth plays a constitutive role in language because both constatives and performatives aim at the truth laid down by the Big Other (which is public and communal property and recognized socially). The performative attempts to transform a situation in the eyes of the Big Other: saying 'I do' at a marriage ceremony does not transform the situation of the couple in isolation, but succeeds only insofar as it is recognized by the community. The constative names a state of affairs successfully only insofar as another (real or presupposed) linguistically capable gaze is there to confirm the proposition - real or presupposed, because like Foucault's panopticon, the Big Other operates even if there is no actual subject occupying its place.

This is why a Lacanian reading of Wittgenstein's critique would point out that Wittgenstein is inaccurately painting a picture of language that works only for psychotics: the psychotic, as defined by Lacan, is the one who never acceded to the domain of the symbolic law (Lacan, 1977, p. 164). That is, he cannot grasp the performative function of language, and is not 'touched' by the gaze of the Big Other. Language there is simply a one-to-one correlation between signs and meanings; he can utilize the complex structure of language, may be able to speak and write very well indeed, but he is not fully caught in language. To complete a full picture of language, one must posit the Big Other in some form, must recognize a gaze or space which grants the power of the performative, or even simply the social gesture. For Augustine, however, this is not just some fantasmatic space, something necessarily posited but that lacks positive being; this is the inner word, mirrored after God's Word, the true source of conventional language and temporal reality itself, respectively.

Here, it is the fictional or conventional which sustains (temporal) reality, though there is an important ontological difference between Lacan and Augustine: beyond convention is pure void for the former, and the fullness of God for the latter. This does not pose a problem for a theory of language specifically, since all that matters is that there is something else, and that the symbolic (and therefore temporal) subject is incomplete. It does preclude, however, certain extensions of the comparison: for Lacan, were the subject to be in the full presence of the Real, his world would dissolve (thus the Real is the impossible for the subject). Lacan's theory of language does not seem to be amenable to a theology, unless it's a Gnostic one (though that is, of course, not the point here).

11 "[What] we have been trying to do is somehow to see him by whom we were made by means of this image which we ourselves are, as through a mirror" (Augustine, 1991, p. 407).

12 Though it is outside the scope of this project, we can see here how the incompleteness of the subject (which mirrors the incompleteness of language and indeed of reality itself) leads to a difference between Lacan and Augustine on love. For Augustine, love occupies a harmonious trinity (lover-object-love), whereas with Lacan we must conclude that the object of desire is the missing part of ourselves that would serve to complete us, except for the fact that he/she doesn't exist.

Language and Psychoanalysis, 2013, 2 (2), 64-76

http://dx.doi.org/10.7565/landp.2013.0007 
Indeed, this allows us to recognize an important methodological difference. The Master Signifier is an 'incarnation' in symbolic language of the failure of the very possibility of full (complete) signification. Lacan moves from the symbolic structure to the Real (from the failure of signification to the remainder), where Augustine moves from the real of the inner word to outer language. If nothing else, this provides an explanation for any possible application of each 'system': Lacan is ultimately concerned with the psychic effect of, and an explanation for, language, whereas Augustine's real desire is to know God Himself.

What I have not attempted to do here is develop a rigorous parallel between the complexities of Lacan's theory of language and Augustine's. There is no doubt that their projects are different: for one, Lacan is not interested in a theory of mind, and Augustine did not have the luxury (or burden) of having Freud or Saussure to work out of. Further, to translate their terms (inner/outer word, Big Other, the Real, etc.) directly into one another would be all too convenient, and would require subordinating the thought of one thinker to the other in the name of strategy. Instead, by showing the similarities between Lacan and Augustine on language (and the subject of language), the structural categories that in some sense transcend the signifier relations, I have traced a path out of the (supposed) deadlock that Wittgenstein attaches to Augustine's theory. And more importantly, if one is predisposed to shrug off Wittgenstein's criticism in the first place, the comparison helps to originate and develop a purely structural (and thus secular) analysis of language that draws on (even if it didn't originate with) Augustine.

\section{Acknowledgments}

I would like to thank my reviewers at Language \& Psychoanalysis for the invaluable comments offered during the stages of this essay's revision.

\section{Biography}

Zachary Tavlin is a Ph.D. candidate in English at the University of Washington. He received his M.A. in Philosophy from Louisiana State University, and his B.A. in Philosophy from The George Washington University. His areas of research include phenomenology, Marxism, psychoanalysis, and film. Forthcoming publications include essays and book chapters on Shakespeare and Levinas, and the fiction of Don DeLillo. 


\section{References}

Alain-Miller, J. (1984). Montre a Premontre. Analytica, 37, 27-31.

St. Augustine, \& Pine-Coffin, R. S (1961). Confessions. Harmondsworth, UK: Penguin.

St. Augustine, \& Green, R. P. H. (1995). De Doctrina Christiana. Oxford, UK: Clarendon.

St. Augustine, Hill, E., \& Rotelle, J. E. (1991) The trinity. Brooklyn, NY: New City.

Barzilai, S. (1999). Lacan and the matter of origins. Stanford, CA: Stanford University Press.

Bergvall, A. (1993). The theology of the sign: St. Augustine and Spenser's legend of holiness. Studies in English Literature, 1500-1900 33, 21-42.

Glejzer, R. (1997). Lacan with scholasticism: Agencies of the letter.” American Imago, 54, 105-122.

Lacan, J. (1977). Écrits: A selection. New York, NY: Norton.

Lacan, J. (1991) The seminar of Jacques Lacan, Book I: Freud's papers on technique (1953-1954). New York, NY: Norton.

Mennel, S. (1994). Augustine's 'I': The 'knowing subject' and the self. Journal of Early Christian Studies, 2, 291-324.

Schildgen, B. D. (1994). Augustine's Answer to Jacques Derrida in the De Doctrina Christiana. New Literary History, 25, 383-397.

Wittgenstein, L. (1953). Philosophical investigations. New York, NY: Macmillan, 1953. Print.

Wittgenstein, L., \& Rhees, R. (1979). Remarks on Frazer's goldenb. Atlantic Highlands, NJ: Humanities.

Zupancic, A. (2012). Not-Mother: On Freud's Verneinung. E-Flux, 33. Retrieved from http://www.e-flux.com/journal/not-mother-on-freuds-verneinung/ 